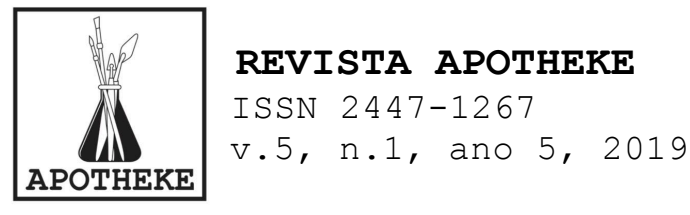

\title{
Pintura, cultura e realidade
}

\author{
Miguel Vassali (UDESC)
}

\begin{abstract}
RESUMO: Este artigo propõe reflexões sobre a arte como área do conhecimento que estuda e propaga cultura. Por esse percurso, os cenários da modernidade e da pós-modernidade sugerem, conforme apresenta Lipovetsky (2004), o avanço da produção de subjetividade pela cultura e pelos sistemas de consumo. Esse avanço influencia os desejos e a formação dos indivíduos. Por isso, Guattari e Rolnik (1996) apresentam as ideias de individualização (esforços da produção de bens em normatizar os grupos em função do consumo) e singularização (conscientizar os indivíduos quanto às subjetividades impostas a fim de criar alternativas de vidas mais autônomas, usando como exemplo o processo artístico). Nesse sentido, expõem-se as ideias de Merleau-Ponty (2013) sobre a matéria-prima da pintura: a cultura e as relações sociais em seus respectivos contextos. Ainda, por meio das reflexões de Sabino (2018), procura-se analisar o papel da pintura como leitura da realidade. A pintura e o fazer artístico nesse cenário podem contribuir na identificação das realidades sociais como um novo processo de percepções e sensibilidades.
\end{abstract}

PALAVRAS-CHAVE: Cultura, pintura, subjetividade, realidade.

RESUMO: This article aims a reflection about art as knowledge area that studies and disseminates culture. Therefore, the scenarios of modernity and postmodernity suggest, as Lipovetsky (2004) presents, the advance of the production of subjectivity through culture and consumption systems. It influences the desires and the formation of individuals. For this reason, Guattari and Rolnik (1996) differentiate the processes of singularization (which intends to make individuals aware of the imposed subjectivities in order to create alternatives for an autonomous life) and individualization (this refers to the efforts of the capitalist production for regulate the groups according with consumption). In this sense, the ideas of MerleauPonty (2013) about the raw material of painting are exposed: culture and social relations in their respective contexts. Also through the texts of Sabino (2018) the role of painting is analyzed as a reading of reality. Painting and artistic work in this scenario can contribute to the identification of social realities as a new process of perceptions and sensibilities

KEY WORDS: Culture, painting, subjectivity, reality.

\section{Cultura e pintura}

As artes representam as interrelações pertinentes à cultura, que é a expressão coletiva do ser humano. Junto a isso, o fazer artístico demonstra a "potência da contextualização" (SILVA; LAMPERT, 2017, p. 92), a qual é multicultural e essencial à consciência de subjetividade. Por conseguinte, a pintura como fazer artístico pode ser um exemplo da interseç̧ão entre arte e cultura. 


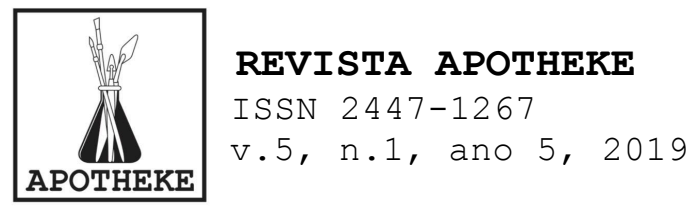

Esse processo artístico representa uma forma de investigação sobre o que se percebe do mundo visível e de que forma se encara a realidade tendo em vista essa subjetividade. Considerando o contexto político atual e, principalmente, o advento do sistema capitalista - cuja influência na produção em série de imagens para diversos fins é gigantesca -, pensar a imagem se torna mais do que necessário. Isso porque as imagens que são impostas ao público produzem um tipo de subjetividade planejada, agindo de forma pretenciosa na condição humana, principalmente pela cultura. Assim, esse processo pode acarretar homogeneização do pensamento e relações socioculturais cada vez mais normatizadas.

Além disso, de acordo com Guattari e Rolnik (1996), o conceito de cultura pode ser profundamente reacionário; é uma maneira de separar atividades semióticas (atividades de orientação no mundo social e cósmicol em esferas às quais os seres humanos são submetidos. Essas atividades podem ser padronizadas e instituídas de forma dependente da fonte dominante.

Portanto, a pintura, como uma maneira de produzir cultura, pode ser fundamental no processo de reconhecimento do contexto sociocultural se forem levadas em consideração as dimensões políticas, discursivas e pedagógicas da experiência artística. Como afirma Lampert (2016), a prática da pintura compreende-se como processo de um fazer criativo no qual se inclui a reflexão crítica e a produção plástica por meio da experimentação (e vice-versa), concebendo que a pintura pode ser uma representação imaginária, mas também aborda derivações sobre a estética.

Nesse cenário, torna-se fundamental a apuração de um olhar crítico voltado à prática cultural vigente, ainda mais tratando-se das imagens que são consumidas na sociedade contemporânea. Esse movimento implica de imediato uma leitura 


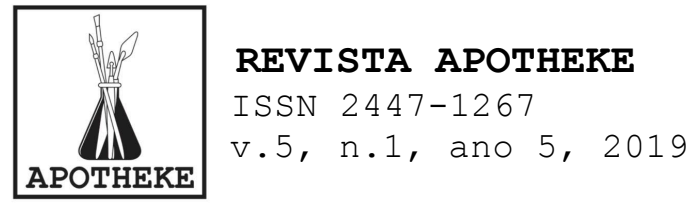

histórica quanto ao desenvolvimento dos sistemas dominantes que influenciam diretamente as organizações sociais ao longo dos anos.

\section{Modernidade e subjetividade}

O autor Gilles Lipovetsky estuda há mais de vinte anos as mudanças que permeiam as relações sociais, com o intuito de elucidar, na dimensão do desenvolvimento cultural, político e social, a passagem do mundo industrial, ou modernidade, para a globalização, ou pós-modernidade. Como exemplo, ele enfatiza que a moda, principalmente na modernidade, empreendeu a tarefa de escapar do mundo da tradição e desempenhou um papel importante na aquisição da autonomia dos indivíduos. Ela possibilitou a "desqualificação do passado e a valorização do novo, a afirmação do individual sobre o coletivo, tudo isso graças à subjetivação do gosto" (LIPOVETSKY, 2004, p. 24).

Devido a esse novo paradigma, conforme Lipovetsky (2004), na teoria, a modernidade calcou-se em dois valores principais: liberdade e igualdade; e trouxe uma figura inédita: o indivíduo autônomo em ruptura com o mundo da tradição. Entretanto, no mesmo período, ampliaram-se o poder estatal e seu controle sobre o povo.

Mais tarde, na pós-modernidade, os mecanismos de controle, para Lipovetsky (2004), não sumiram, adaptaram-se na medida em que a busca de independência por parte dos indivíduos e a valorização da autonomia estão diretamente ligadas à prosperidade da indústria e à socialização do consumo. Tem-se, nessa dinâmica, um paradoxo de que a maior parte dos valores que emanciparam o indivíduo estabeleceu uma forma de democracia que funciona essencialmente dentro do sistema capitalista, uma democracia relacionada à liberdade de consumo. 


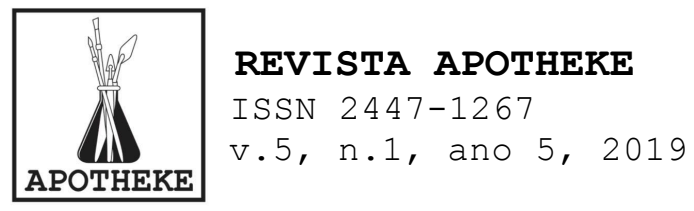

Consequentemente, o fomento da indústria influenciou de forma significativa a produção artística, principalmente no que diz respeito aos investimentos em pesquisa e educação para fomentar esse mercado. A partir disso, a cultura de massa passou a ser um dos principais aliados da indústria e intensificou a produção de imagens para entretenimento, como o cinema, a televisão, a publicidade etc.

De maneira análoga, de acordo com Guattari e Rolnik (1996), a publicidade e a cultura de massa produzem essencialmente indivíduos, normalizados, articulados, uns com os outros, em sistemas hierárquicos, sistemas de valores e sistemas de submissão.

[...] os jovens que passeiam pelas ruas equipados com um walkman estabelecem com a música uma relação que não é natural. A indústria altamente sofisticada, ao produzir esse tipo de instrumento (tanto como meio quanto como conteúdo de comunicação), não está fabricando algo que simplesmente transmita uma música ou organize sons naturais. O que essa indústria faz é, literalmente, inventar um universo musical, uma outra relação com os objetos musicais: a música que vem de dentro e não de um ponto exterior. Em outras palavras, o que ela faz é inventar uma nova percepção.

Outro exemplo, são as experiências feitas por antropólogos em sociedades ditas primitivas. Eles apresentaram vídeos para algumas tribos, e constataram que o vídeo era olhado como um objeto até divertido, mas como outro qualquer. Essa reação nos mostra que o tipo de comportamento que consiste em ficar inteiramente focalizado no aparelho, ou uma relação de comunicação direta, só existe em nossa sociedade. É ela que o produz. (GUATTARI; ROLNIK, 1996, pp. 32-33).

Ou seja, os autores apontam que a subjetividade está em circulação nos conjuntos sociais, é assumida e vivida por indivíduos de duas formas: em alienação, na qual o indivíduo se submete a subjetividade tal como a recebe; ou em uma relação de expressão e de criação, na qual o indivíduo se reapropria dos componentes da subjetividade e produz o que os autores chamam de singularização. O que descreve efetivamente 


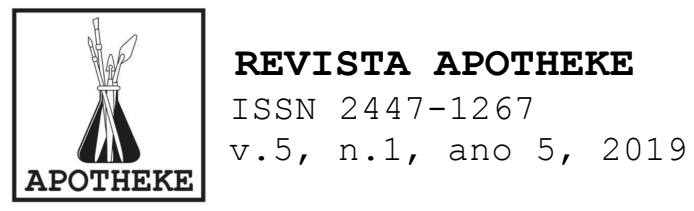

um processo de singularização é o fato de ele ser automodelador; é preciso que seja responsável por captar os elementos de uma determinada situação e, assim, consiga construir seus próprios tipos de referências práticas e teóricas.

Adicionalmente, Guattari e Rolnik (1996) salientam que esses microprocessos revolucionários não precisam ser necessariamente de natureza das relações sociais. Para eles, a relação do indivíduo com a música ou com a pintura pode acarretar um processo de sensibilidade e percepção da realidade inteiramente novos.

\section{A pintura como leitura da realidade}

Identificam-se, ao longo da história, diversos autores, artistas ou entusiastas das artes que elaboraram teorias variadas a respeito do processo artístico e especificamente da pintura e suas relações com a cultura e a percepção da realidade. Como exemplo, Maurice Merleau-Ponty, um dos pioneiros das teorias relacionadas à fenomenologia, escreveu sobre a percepção da pintura e do ato de pintar, destacando, em seus textos dedicados ao assunto, alguns escritos de André Maulraux.

Sobre alguns trechos desses escritos, Merleau-Ponty (2013) comenta que as teorias da representação na arte foram e são os pilares do estudo acadêmico das imagens. Conforme o autor, há uma frequente divisão na história da arte quanto ao intuito de representação na pintura dos artistas ditos clássicos em relação à produção artística desenvolvida durante a era moderna. A pintura clássica jamais constituiu um simples representar.

É isso que faz com que as obras clássicas tenham um sentido diferente e talvez mais sentido do que os pintores julgavam, com que muitas vezes elas antecipem uma pintura liberta de seus cânones e permaneçam os 


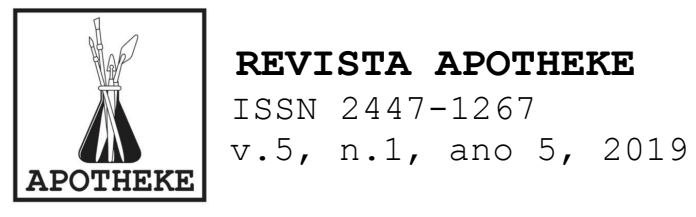

intercessores adequados de qualquer iniciação à pintura.
No momento em que, com os olhos fixos no mundo, julgavam
pedir-lhe o segredo de uma representação suficiente,
elas operavam sem saber essa metamorfose de que mais
tarde a pintura tornou-se consciente. Mas então não se
pode definir a pintura clássica pela representação da
natureza ou pela referência a "nossos sentidos", nem
portanto a pintura moderna pela referência ao subjetivo.
Já a percep̧ão dos clássicos se prendia à cultura deles,
a nossa cultura ainda pode informar a nossa percepção do
visível; não se deve abandonar o mundo visível às
receitas clássicas, nem encerrar a pintura moderna no
reduto do indivíduo, não se tem de escolher entre o
mundo e a arte, entre os "nossos sentidos" e a pintura
absoluta: estão todos entrelaçados. (MERLEAU-PonTr,
2013. p. 72).

Esse estudo possui uma grande importância no campo da pintura, não somente porque ele coloca em xeque as teorias relacionadas à representação ou ao seu teor elucidativo no que concerne aos movimentos artísticos e suas ligações com a sociedade, mas também porque estabelece a cultura e a leitura subjetiva de mundo dos artistas de determinada época como matéria-prima da produção artística.

Nesse mesmo caminho, Isabel Sabino, artista e professora da Universidade de Lisboa, salienta a questão complexa da utilidade da pintura no real, ou seja, é "impossível libertarse da relação com o seu carácter mais ou menos inovador ou da sua eficácia política" (SABINO, 2018, p. 38). Além disso, a crise de sobrevivência da pintura na arte moderna e contemporânea é inerente a essa questão.

\begin{abstract}
Pensar a realidade com a pintura parece, entretanto, mais problemático desde os anos sessenta, em especial quando a viabilidade da pintura e a sua utilidade no mundo real constituem temas recorrentes, com destaque para os defensores radicais de novas modalidades sob a lógica da obsolescência da pintura e para artistas cuja produção pictórica envolve a representação figurativa mediante compromisso social ou político. (SABINO, 2018. p. 36 )
\end{abstract}

Considerando-se a questão da viabilidade da pintura, é fato que praticamente todos os artistas questionaram a função 


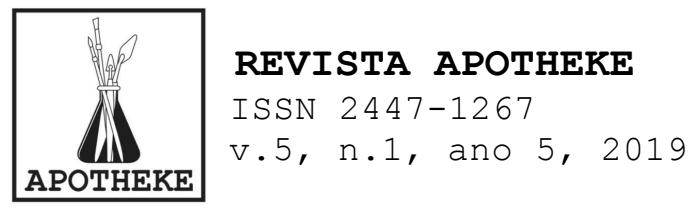

da representação do visível quando esta perdeu muito de seu sentido prático após a invenção da fotografia. Para sanar esse impasse, o percurso autorreflexivo indaga sobre novas "dimensões e utopias do mundo e do conhecimento, incluindo o espaço do inconsciente, o absurdo e o esforço de concretização de uma linguagem universal da qual a abstração é um dos sintomas" (SABINO, 2018, p. 39).

A título de exemplo, o trabalho com abstração do artista Mark Rothko (1903-1970) não procura a imagem direta da realidade. Sabino (2018), por sua vez, afirma que o artista encara um dilema insolúvel na sua relação com o mundo, marcado por inúmeras questões, como a sobrevivência ou o desejo de agradar os outros. Dessa forma, Rothko (2007) frisa que um quadro é uma afirmação das ideias do real do artista, feita nos termos do seu discurso plástico. Assim, o pintor pode ser comparado mais ao filósofo do que ao cientista.

Sabino (2018) expõe, portanto, que não se trata, em pintura, de operar simulacros e esperar que eles se confundam com a realidade ou até que a substituam. Se, como espécie humana, há intempéries no plano social e cultural, é no plano do conhecimento, da tecnologia sustentada e da lucidez política, ancorada no humanismo, que o futuro se decide. Com isso, a autora sugere a existência de muitos modos da arte e da pintura contemporânea funcionando nesse plano, mesmo que não seja apenas isso que defina o seu papel na realidade.

Também Antoni Tàpies (1923-2012), autor de uma pintura matérica e sígnica de forte despojamento figurativo e igualmente dotado na expressão escrita, assume forte compromisso social e concentra-se na afirmação da própria realidade como arte e, por outro lado, da arte como modo de conhecimento para um melhor entendimento do real. Conforme diz, "a grande luta empreendida pelo homem para ir ajustando a sua concepção da realidade (...) não pode prosperar se se manipularem ideias que já foram concebidas ou que se realizaram anteriormente". Será assim o artista realista, alguém de visão lúcida e razoável, capaz de um entendimento maleável e inovador, que se apercebe da necessidade de reajustar o que lê. E, 


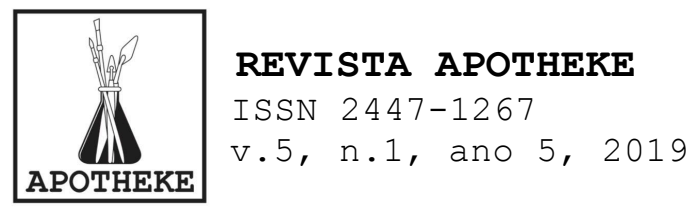

\begin{abstract}
nesse sentido, assume que na sua própria obra "há uma rejeição de certas realidades" como as que a publicidade anuncia, preconizando uma escolha personalizada e consciente (um pouco no sentido do julgamento que já Poussin defendia) quando afirma, por exemplo, que há "que reencontrar a autêntica cor do mundo, a que não está falseada pela banalidade publicitária. A cor em si não existe. Necessito de uma cor interior". (SABINo, 2018. p. 37)
\end{abstract}

Essa abordagem da pintura como pensamento do real pode sugerir a criação de caminhos singulares com base no mapeamento do contexto social e dos sistemas de dominação. Exposta por Guattari e Rolnik (1996), essa maneira de criar pode refletir-se em um fazer artístico da ordem do saberfazer, da experimentação e do movimento entre percepção, crítica e criação.

Encontra-se um exemplo desse processo em um dos eventos artísticos mais essenciais da história da arte do Brasil e, principalmente, da pintura brasileira. Nos anos 80, a exposição chamada "Como vai você, geração 80?", de curadoria de Paulo Roberto Leal, Marcus Lontra e Sandra Mage, reuniu aproximadamente 123 jovens artistas. Coincidindo com o pluralismo político que nascia no Brasil na época, esses jovens artistas representaram em suas obras o grito abafado da arte durante o período militar. Não suportavam mais a repressão da imaginação e da criação artística. A pintura, então, exerceria um papel importante nesse momento: questionada pelos movimentos de desmaterialização da arte e da arte conceitual muito difundidos nas décadas anteriores, a imagem voltou a ocupar um lugar de destaque na produção do período.

Devido a essa nova valorização da imagem, um intenso intercâmbio de ideias e experiências conjuntas gerou obras que indicavam a relação reflexiva e pessoal de cada aluno artista (SÃO PAULO, [s.d]). Esse processo pode ser visto como um movimento de singularização exposto por Guattari e Rolnik 


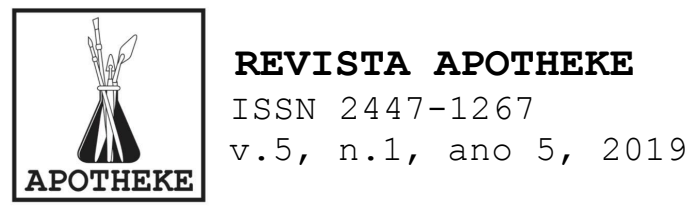

(1996), principalmente no que concerne ao processo criativo como uma percepção pessoal sobre a organização política, social e cultural do período e a exploração do processo artístico como experiência da vida íntima.

Não por coincidência, a pintura retorna para o cenário artístico com grande potencialidade, defendida como pesquisa, principalmente dos afetos. As relações afetivas encontradas nos trabalhos são um dado importantíssimo na produção e norteiam a relação com as imagens, que são rearranjadas sem qualquer hierarquia, criando arquivos pessoais, bibliotecas íntimas, diários de viagem etc.

\section{Reflexões finais}

Para o artista professor, é fundamental o discernimento quanto à organização social vigente, principalmente no que diz respeito à cultura como sendo fenômeno de estudo da arte como área do conhecimento.

Essa análise não pretende responsabilizar o artista professor como agente de uma denúncia política, muito menos pretende teorizar de forma pessimista sobre uma "decadência" social representada pela globalização do sistema capitalista. Sabe-se que, no mundo contemporâneo, vive-se inserido em intrincadas organizações políticas, sociais, culturais; seria humanamente impossível prever ou agir sobre encaminhamentos de ordem mundial.

A discussão que esse estudo apresenta está relacionada com uma tomada de consciência quanto à produção artística como percepção da realidade de cada indivíduo e de um sistema homogeneizador dominante. Tal como os textos de Guattari e Rolnik (1996) sugerem, a subjetividade é própria do indivíduo, mas funciona essencialmente em uma esfera social. A ideia central é apropriar-se dos sistemas de representação que já foram usados pelos grupos dominantes, institucionalizados ou 


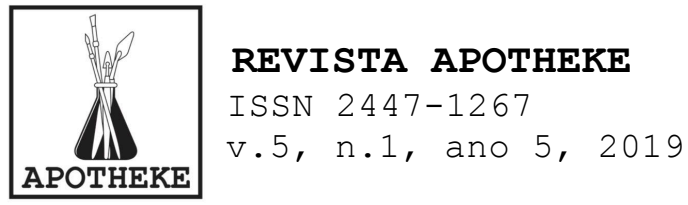

não, e reaver os próprios desejos de maneira autônoma e genuína.

A experiência artística revela, dentro dessa discussão, uma oportunidade de flexionar a sensibilidade, a percepção e, principalmente, o trabalho criativo, de maneira a não somente produzirem-se imagens que proponham reflexões, mas entender esse processo, esse pensamento constitutivo: de onde as imagens vêm, o que elas representam e o que pode ser feito com elas.

A pintura, nesse cenário, é uma aliada, porque afirma um processo artístico e tem uma ligação íntima com a construção de imagens. Essas imagens podem ser identificadas e selecionadas conforme a subjetividade de cada ser, e articuladas novamente conforme suas relações. Não necessariamente este processo é caracterizado pela pintura de natureza figurativa, mas objetiva uma leitura das realidades individuais no formato de imagens e uma transformação das mesmas através do processo artístico. Dessa forma, é possível viabilizar as transformações das paisagens tanto reais quanto fictícias, visando um domínio crítico da percepção e a criação de caminhos para as vidas individuais que estejam em conformidade com os contextos singulares e específicos de cada indivíduo.

\section{REFERÊNCIAS}

GUATTARI, Félix; ROLNIK, Suely. Micropolíticas: cartografias do desejo. 4. ed. Rio de Janeiro: Editora Vozes, 1996.

LAMPERT, Jociele. [Entre paisagens] ou sobre 'ser' artista professor. In: Cadernos de Pesquisa - Pensamento Educacional. Revista do Programa de Pós-

Graduação em Educação UTP. Dossiê: arte e educação: abordagens e

perspectivas. Paraná: Curitiba, 2016, v. 11, n. 29. ISSN: 2175-2613.

LIPOVETSKY, Gilles. Os tempos hipermodernos. São Paulo: Barcarolla, 2004. $129 \mathrm{p}$.

MERLEAU-PONTY, Maurice. o olho e o espírito. 1. ed. São Paulo: Cosac Naify, 2013 . 


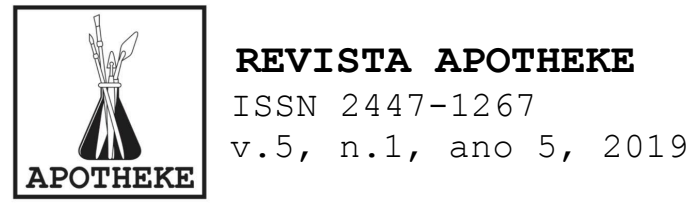

ROTHKO, Mark. A realidade do artista. Filosofias da arte. Lisboa: Cotovia, 2007 .

SABINO, Isabel Maria. Four seasons, please! \#3: A realidade, a pintura e algum cinema. Porto Arte: Revista de Artes Visuais. Porto Alegre: PPGAVUFRGS, v. 23, n. 39, p.31-45, jul.-dez. 2018. e-ISSN 2179-8001.

SÃO PAULO. Universidade de São Paulo. Museu de Arte Contemporânea. Acervo do MAC on-line. Como vai você, Geração 80? In: Arte do século XX/XXI: visitando o MAC na web. [s.d.]. Disponível em:

http://www.mac.usp.br/mac/templates/projetos/seculoxx/modulo6/vaivc/index.h tml. Acesso em: 20 fev. 2019.

SILVA, Tharciana Goulart da; LAMPERT, Jociele. Reflexões sobre a Abordagem Triangular no Ensino Básico de Artes Visuais no contexto brasileiro.

Revista Matéria-Prima. Lisboa, 2017, v. 5 n. 10 . ISSN 2182-9756 e-ISSN $2182-9829$.

Miguel Vassali

http://lattes. cnpq.br/1573499434997969

Miguel Vassali é formado em Design (UNOESC), graduando de Artes Visuais Licenciatura (UDESC) e bolsista do programa de extensão grupo de estudos Estúdio de Pintura Apotheke. 